\title{
STUDY OF THICK FILM RESISTORS BY 1/f NOISE MEASUREMENTS
}

\author{
A. AMBRÓZY, E. HAHN, L.B. KISS* and G. TREFÁN* \\ Technical University, Budapest, H-1521, Hungary \\ * JATE University, Szeged, H-6720, Hungary \\ (Received May 7, 1988; in final form August 8, 1988)
}

Knowledge on the conduction mechanism of thick film resistors are limited and often contradictory.

In this paper investigations based on temperature dependent $1 / \mathrm{f}$ noise measurements are reported.

\section{INTRODUCTION}

Numerous efforts have been made to understand the conduction and noise mechanisms of thick film resistors but until now a model without contradictions is not available $\mathrm{e}^{1-6}$.

There are two extreme views:

a) Conduction and noise are determined by the contacts between conducting grains embedded into the glass [e.g., ref. 3]; according to this model the most determining factor is the small effective area of contact

b) Conduction and noise are determined by the dopants (or impurities) within the glass [e.g., ref. 4]. Some models tried to include both mechanisms [e.g., refs. 2, 5].

It is important to note that for a satisfactory description not only a) and b) should be taken into consideration but also the results of generalized percolation theory. Percolation effects may increase the fluctuations of resistance and under proper conditions they may even influence the shape of the spectrum. Special attention should be devoted to the fractal dimension character of the system topology and to the effect of the diffusion controlling the conductivity including possible anomalous diffusion ${ }^{7}$. 
In this paper we try to collect information about the conductivity mechanism of thick film resistors by temperature dependent $1 / \mathrm{f}$ noise measurements.

\section{THEORY}

In [ref. 8] a method is proposed for the temperature dependence carrier concentration $\mathrm{n}(\mathrm{T})$ and mobility $\mu(\mathrm{T})$ :

$\frac{\mathrm{n}(\mathrm{T})}{\mathrm{n}\left(\mathrm{T}_{0}\right)}=\left[\frac{\mu_{\mathrm{L}}^{2}\left(\mathrm{~T}_{0}\right)}{\mu_{\mathrm{L}}^{2}(\mathrm{~T})} \cdot \frac{\alpha_{\mathrm{H}}(\mathrm{T})}{\alpha_{\mathrm{H}}\left(\mathrm{T}_{0}\right)}\right]^{\frac{1}{3}} \cdot\left[\frac{\mathrm{S}_{\mathrm{R}}\left(\mathrm{f}, \mathrm{T}_{0}\right)}{\mathrm{S}_{\mathrm{R}}(\mathrm{f}, \mathrm{T})}\right]^{\frac{1}{3}}$

and

$\frac{\mu(T)}{\mu\left(T_{0}\right)}=\left[\frac{\mu_{L}^{2}(T)}{\mu_{L}^{2}\left(T_{0}\right)} \cdot \frac{\alpha_{H}\left(T_{0}\right)}{\alpha_{H}(T)} \cdot \frac{n\left(T_{0}\right)}{n(T)}\right]^{\frac{1}{4}} \cdot\left[\frac{S_{G}(T, f)}{S_{G}\left(T_{0}, f\right)}\right]^{\frac{1}{4}}$

where $\mu_{\mathrm{L}}(\mathrm{T})$ is the (temperature dependent) lattice scattering mobility, $\alpha_{H}(T)$ the noise (Hooge) factor lattice scattering, $S_{R}(f, T)$ the measured resistance noise spectrum and $S_{G}(f, T)$ is related to the measured conductance noise spectrum, $S_{G}(f, T) / R^{4}(T)$, where $R(T)$ is the sample resistance. The first factors in equations (1) and (2) are usually unknown. However, the temperature dependence of $\mu_{\mathrm{L}}$ often can be estimated and that of $\alpha$ is usually weak ${ }^{9}$ or saturating ${ }^{10}$. Additionally, it should be noted that the temperature dependence of these terms is reduced by the powers $1 / 3$ and $1 / 4$, respectively.

We note that Eqs (1) and (2) are valid only for the cases where Ohm's law and the Hooge-Vandamme formula given by the equation;

$\frac{\mathrm{S}_{\mathrm{R}}(\mathrm{f}, \mathrm{T})}{\mathrm{R}^{2}(\mathrm{~T})}=\left[\frac{\mu(\mathrm{T})}{\mu_{\mathrm{L}}(\mathrm{T})}\right]^{2} \cdot \frac{\alpha_{\mathrm{H}}(\mathrm{T})}{\mathrm{n}(\mathrm{T}) \mathrm{V}_{\mathrm{eff}}} \cdot \frac{1}{f^{\varkappa}}$

hold for the sample material, where $\varkappa \rightarrow 1$ and $V_{\text {eff }}$ is the effective noise volume of the sample ${ }^{9}$.

In thick film resistors both Ohm's law and Hooge's classical 1/f Eqs. (1) and (2) were obtained from Eq. (3) and Ohm's law by elementary calculations ${ }^{8}$. In thick film resistors both Ohm's law and Hooge's classical $1 / \mathrm{f}$ noise formula are valid ${ }^{1}$. However, the validity 
of the Hooge-Vandamme formula (containing also a reduction factor of the squared ratio of actual and lattice scattering mobilities) is still open. Nevertheless, as it is mentioned in [ref. 11], for the square relationship between noise and mobility (that is, for the validity of Eq. (3)) it is enough to postulate a scattering mechanism which is responsible for mobility fluctuation leading to $1 / \mathrm{f}$ noise but is not dominant in determining the mean resistivity. Eq. (3) has turned out to hold, even in bismuth films made by several deposition methods and in wires ${ }^{12,13}$.

At present, at very limited knowledge on the conduction mechanism of thick film resistors, a natural question is whether the temperature dependence of carrier concentration and mobility given by Eqs. (1 and 2), are consistent with physical expectations.

\section{EXPERIMENTAL}

Excess noise measurements have been done on five different samples, provided by Microelectronics Company (MEV), Budapest, Hungary in the temperature range of $298-373 \mathrm{~K}$. The experimental setup reported in [ref. 14] was applied.

The samples were made on $96 \%$ alumina substrates with the usual firing temperature of $850^{\circ} \mathrm{C}$. The lower resistance values (several ten kiloohms) are of a $10 \mathrm{k} \Omega / \mathrm{square}$ ink, the higher values of 100 $\mathrm{k} \Omega$ /square. The length/width radio is always $>1$. The ink brand is $R X$ 8000 Remex.

A slight temperature dependence of the shape of $S_{R}(f, T)$ was observed which turned out to be sample dependent. Therefore in Eqs. (1) and (2) the cumulated spectrum between $200 \mathrm{~Hz}$ and $2 \mathrm{kHz}$ was applied to reduce the errors coming from the above effect and from stochastic nature of the measurements.

In Eqs. (1) and (2) the lattice scattering mobility was taken into account with the proportionality of $\mu_{\mathrm{L}}(\mathrm{T}) \propto \mathrm{T}^{-3 / 2} 15$. This is valid for acoustical phonon scattering at ordinary temperatures.

\section{RESULTS AND CONCLUSIONS}

The relative temperature dependence of the carrier mobility given by Eq. (2) can be seen in Fig. 1. The function $\mu_{\mathrm{r}}(\mathrm{T})$ lies roughly 


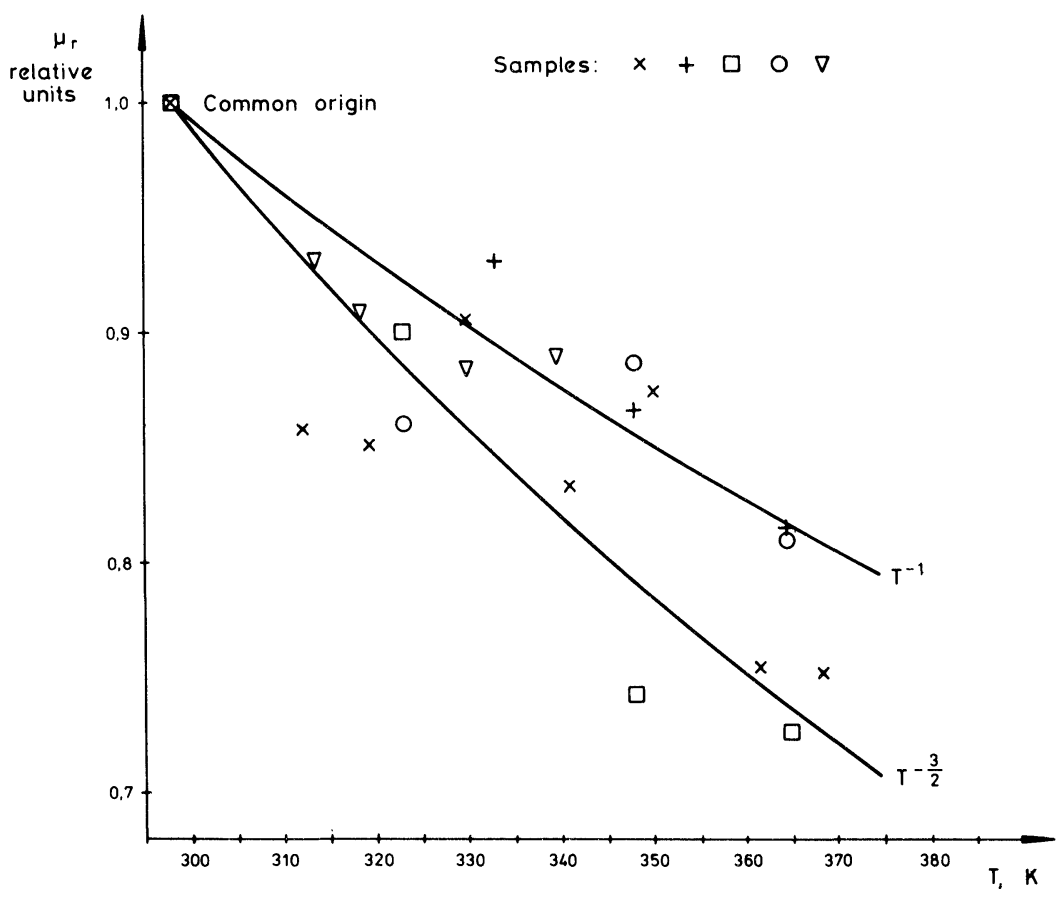

Figure 1 Relative mobility $\mu_{\mathrm{r}}$, versus temperature for 5 different samples.

between $\mathrm{T}^{-1}$ and $\mathrm{T}^{-3 / 2}$. The temperature dependence of the concentration given by Eq. (1) is not drawn since our samples have a practically constant resistance and hence $\mathrm{n}_{\mathrm{r}}(\mathrm{T})$ is the reciprocal of $\mu_{\mathrm{r}}(\mathrm{T})$.

Thus, it can be concluded that the results given by Eqs. (1) and (2) are plausible: the dependence of mobility on $\mathrm{T}^{-1}-\mathrm{T}^{-3 / 2}$ and the slightly rising concentration with temperture resembles the behaviour of degenerated semiconductors. Regarding the models of the conduction mechanism in thick film resistors the following conclusion can be drawn provided Eq. (3) is valid for this system. The temperature dependence of mobility refers to the presence of scattering mechanisms so the hopping models (with increasing mobility vs. temperature) can be excluded. It is interesting to note that a system obeying the "barrier dominated model" 5 would have the same properties as described above. 


\section{REFERENCES}

1. S. Demolder and A. van Calster, "A model for the electrical conduction and $1 / \mathrm{f}$ noise in cermet thick film resistor systems". Noise in Physical Systems and 1/f Noise (Eds. A. D'Amico and P. Mazetti), North Holland 1986, pp. 145-148.

2. B. Pellegrini, R. Saletti, P. Terrini and M. Prudenziati, " $1 / \mathrm{f}$ noise in thick-film resistors as an effect of tunnel and thermally activated emissions, from measurements versus frequency and temperature", Phys. Rev. B27, 1233 (1983).

3. L.K.J. Vandamme, Criteria of low noise thick film resistors", Electrocomp. Sci. Technol 4, 171 (1977).

4. A. Kusy and A. Szpytma, "Sources of $1 / \mathrm{f}$ noise in $\mathrm{RuO}_{2}$-based thick resistive films" ibid as [ref. 1], p. 429-432.

5. A. Ambrózy, " $1 / \mathrm{f}$ noise in $(\mathrm{BaSr}) \mathrm{TiO}_{3}$ (Barrier dominated contact noise", IEEE Trans. ED 28, 344 (1981).

6. R.P. Agarwal, A. Ambrózy, P. Bánlaki, G. Harsányi, G. Katona and V. Kolonits, "Noise measurements on thick-film gas sensors", Noise in Physical Systems (Ed. C.M. Van Vliet), World Scientific 1987, pp. 117-120.

7. A.-M.S. Tremblay and B. Fourcade, "Noise in metal-insulator composites", ibid as [ref. 6], pp. 59-69.

8. L.B. Kiss, M.I. Török and I. Hevesi, "New, more accurate methods for the investigation of the free carrier concentration and mobility by $1 / \mathrm{f}$ noise measurements", Sol. State Comm. 61, 731 (1987).

9. F.N. Hooge, T.G.M. Kleinpenning and L.K.J. Vandamme, "Experimental studies on 1/f noise", Rep. Prog. Phys. 44, 479 (1981).

10. P. Dutta and P.M. Horn, "Low-frequency fluctuation in solids: $1 / \mathrm{f}$ noise", Rev. Mod. Phys 53, 497 (1981).

11. L.B. Kiss and T. G. M. Kleinpenning, "Interpretation of Hooge's 1/f noise formula", Physica 145B, 185 (1987).

12. F.N. Hooge, J. Kedzia and L.K.J. Vandamme, "Boundary scattering and 1/f noise", J. Appl. Phys. 50, 8087 (1979).

13. D.M. Fleetwood, D.E. Beutler, J.T. Masden and N. Giordano, "The role of temperature in sample-to-sample comparisons of the $1 / \mathrm{f}$ noise of metal films", $\mathrm{J}$. Appl. Phys. 61, 5308 (1987).

14. A. Ambrózy, "Noise measurements on thick film resistors", ibid as [ref. 1], pp. $65-69$.

15. R.A. Smith, Semiconductors (University Press, Cambridge 1961). 

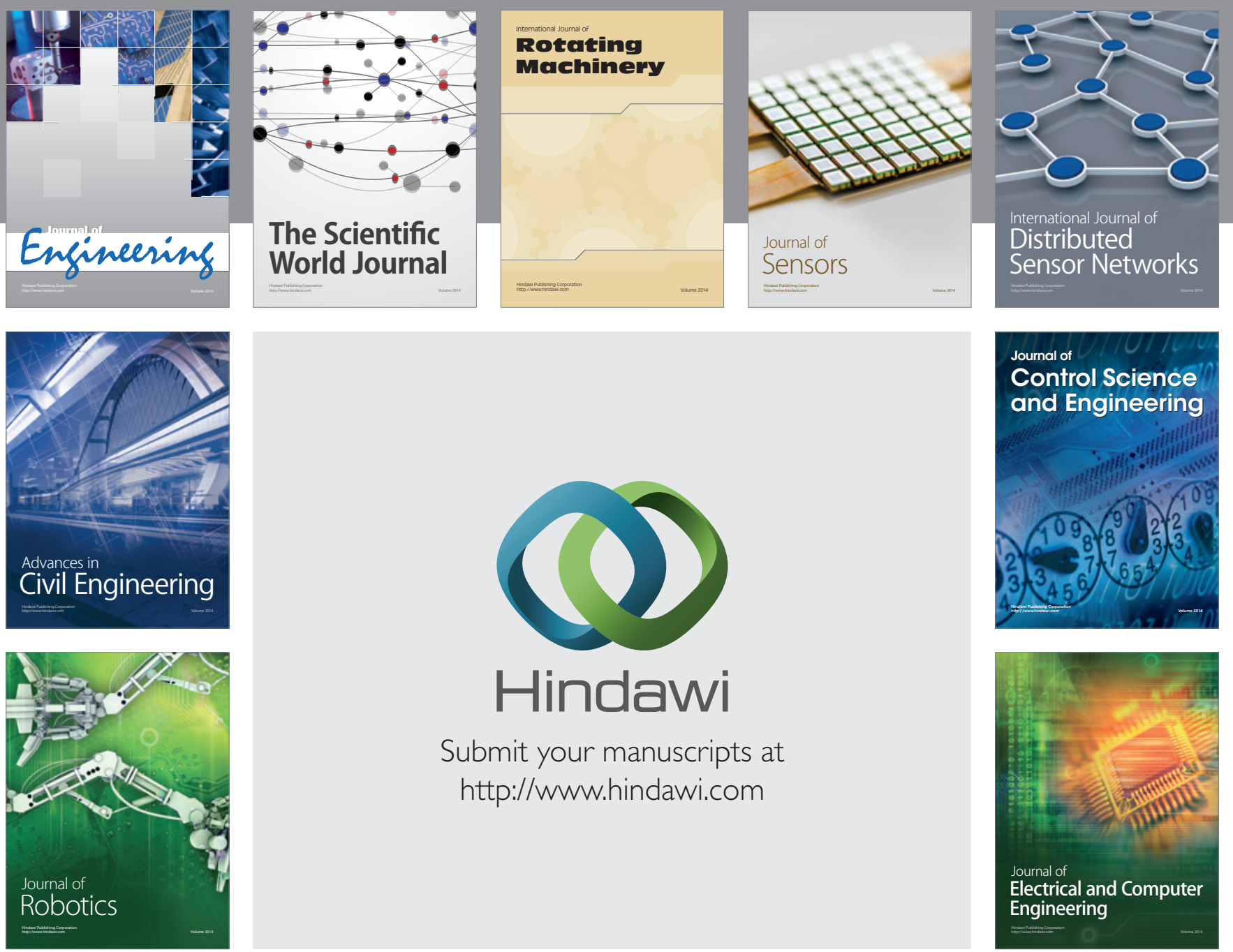

Submit your manuscripts at

http://www.hindawi.com
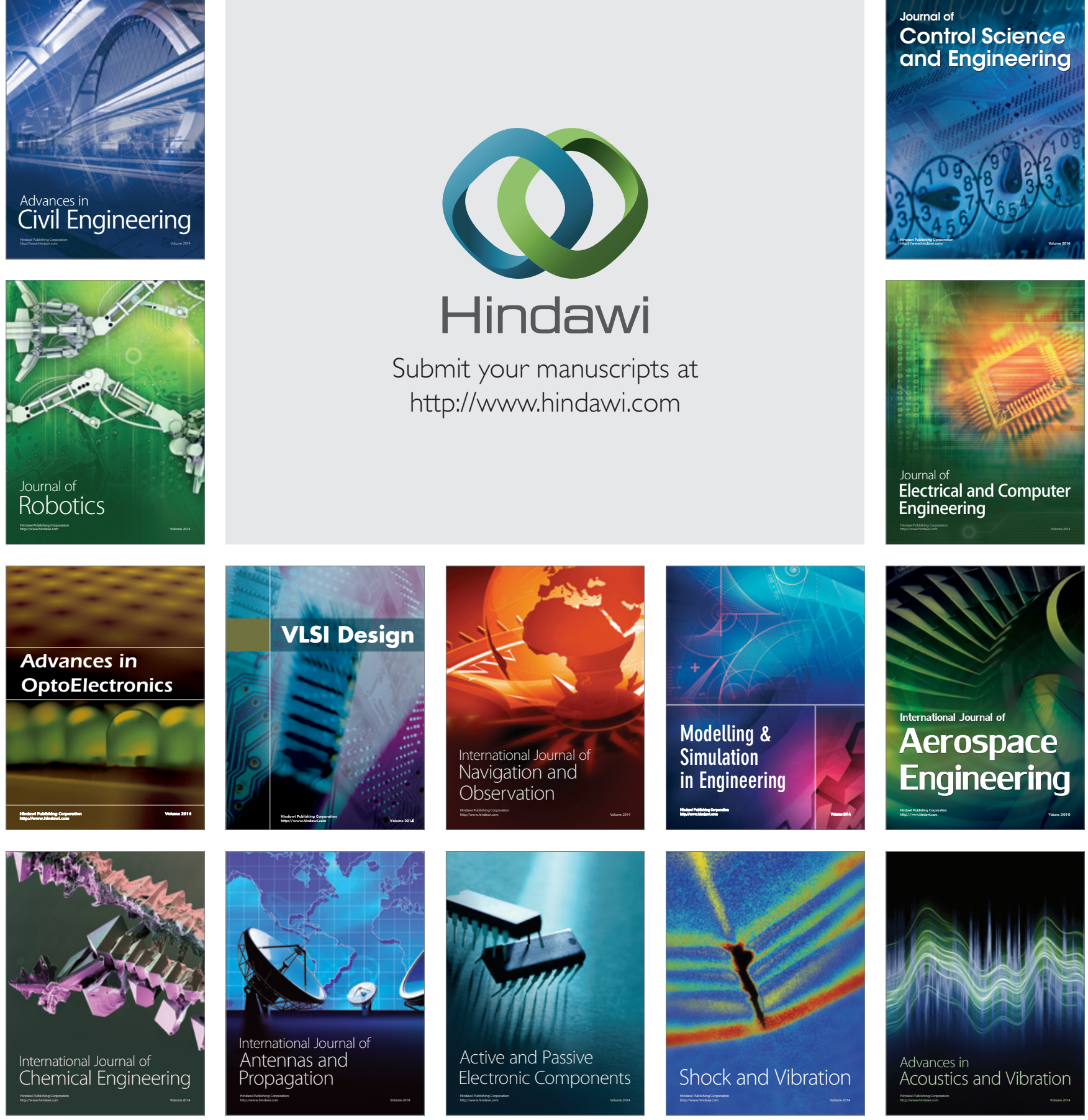